EXTENDED REPORT

\title{
Endothelin-1 concentration is increased in the aqueous humour of patients with exfoliation syndrome
}

\author{
G G Koliakos, A G P Konstas, U Schlötzer-Schrehardt, G Hollo, D Mitova, D Kovatchev, \\ S Maloutas, N Georgiadis
}

See end of article for authors' affiliations .....................

Correspondence to: Associate Professor G Koliakos, PO BOX 17034, 54210 Thessaloniki, Greece; koliakos@med.auth.gr

Accepted for publication 1 September 2003
Background/aim: Endothelin 1 (ET-1) is considered the most potent vasoconstrictor in the body and the eye. This molecule may play a significant role in the pathobiology of exfoliation syndrome (XFS), a disorder characterised by a progressive iris vasculopathy. The purpose of this study was to investigate the concentration of ET-1 in the aqueous humour of cataract patients with and without XFS.

Methods: Aqueous humour samples were obtained from 25 consecutive eyes of 25 cataract patients with XFS and an equal number of age matched controls during phacoemulsification cataract surgery. None of the subjects had elevated intraocular pressure or glaucoma. ET-1 concentration in the aqueous was measured using a specific immunoassay with $100 \%$ immunoreactivity for ET-1. Total aqueous humour protein concentration was measured with a microplate Coomassie blue based method and was correlated with ET-1 concentration.

Results: Mean ET-1 concentration in the XFS aqueous samples (4.6 (SD 2.3) pg/ml) was significantly higher than that measured in the age matched control samples $(2.8(S D 1.71) \mathrm{pg} / \mathrm{ml}) ;(p=0.006)$. Although total protein concentration was significantly elevated in the XFS samples $(0.380$ (SD 0.159$) v$ 0.279 (SD 0.144) $\mathrm{mg} / \mathrm{ml}$ in the controls); $(p=0.023)$, no correlation was found between aqueous ET- 1 and total protein concentration $(p=0.730)$.

Conclusion: The increased concentration of ET-1 in the aqueous humour of XFS patients suggests that ET- 1 may play a role in the pathobiology of XFS.
L xfoliation syndrome (XFS) is an age related extracellular matrix disorder, which often leads to the development of exfoliative glaucoma, (XFG) a distinct form of open angle glaucoma with worse prognosis than primary open angle glaucoma (POAG). ${ }^{2}$ The main characteristic of XFS is the progressive accumulation of a fibrillar extracellular material (exfoliation material) in ocular and systemic tissues. The precise pathogenetic mechanism responsible for the development of XFS and its progression to XFG remain, as yet, poorly understood. ${ }^{23}$

Recent studies on aqueous humour composition in XFS have provided evidence that oxidative stress may play a major role in the pathogenesis of XFS. Firstly, a lower concentration of ascorbic acid, the major antioxidant and free radical scavenger in the eye, has been documented in the aqueous humour of patients with XFS. ${ }^{45}$ Subsequently, the aqueous level of 8-isoprostaglandine F2a (8-IsoPGF $2 \mathrm{a})$, a marker of oxidative stress, was found to be five times higher in XFS than in control samples and its increased concentration correlated well with the reduction in ascorbic acid concentration in the same sample. ${ }^{5}$ Recently, matrix metalloproteinase 2 (MMP 2) was reported to be higher in the aqueous of XFS and XFG patients. ${ }^{67}$ It has been established that 8 IsoPGF $_{2 a}$ promotes the secretion of endothelin- 1 (ET- 1$),{ }^{8}$ and MMP 2 promotes the conversion of ET-1 from its precursor protein, big endothelin. ${ }^{9}$

ET-1 is a 21 amino acid peptide with mitogenic properties, which is considered to be the most potent vasoconstrictor in the body. In the human eye, ET-1 has been shown to be involved in the modulation of ocular blood flow and in the regulation of intraocular pressure (IOP) by constricting the trabecular meshwork, and to a lesser degree the ciliary muscle via $\mathrm{ET}_{\mathrm{A}}$ receptor activation. ${ }^{10-16}$
Endothelin like immunoreactivity has been detected in the human aqueous humour since $1992 .{ }^{17}$ ET-1 is actively secreted by human non-pigmented ciliary epithelial cells into the aqueous humour ${ }^{17}$ leading to a 3-4 times higher level of endothelin like immunoreactivity in the aqueous humour than that found in the plasma of healthy subjects. ${ }^{17}$ In previous in vivo animal experiments laser stimulation of the uveal tissues induced an immediate and pronounced ET-1 release into the aqueous humour. ${ }^{18-21}$ The stimulated ET-1 release caused a significant acute rise in IOP, which was preventable with intracameral pretreatment with a specific $\mathrm{ET}_{\mathrm{A}}$ receptor blocker. ${ }^{22}$ Furthermore intracameral injection of ET-1 in rabbits resulted in a temporary increase in IOP that was followed by a prolonged IOP reduction. ${ }^{23}$

Endothelin like immunoreactivity has been found to be higher in the aqueous humour of patients with POAG and cataract compared with cataract controls, ${ }^{24}{ }^{25}$ which implies a role for endothelins in IOP regulation in the human eye.

To date the level of ET- 1 in the aqueous humour of patients with XFS, or XFG, has not been evaluated, and the possible role of ET-1 in the pathophysiology of XFS has not been elucidated. We therefore investigated ET-1 concentration in the aqueous humour of age matched cataract patients with and without XFS.

Abbreviations: E-1, endothelin-1; IOP, intraocular pressure; MMP 2, matrix metalloproteinase 2; POAG, primary open-angle glaucoma; XFG, exfoliative glaucoma; XFS, exfoliation syndrome 


\section{PATIENTS AND METHODS \\ Sample collection}

Aqueous humour samples were collected at the Department of Ophthalmology, Medical University of Varna, Bulgaria and the University Department of Ophthalmology, Aristotle University, Thessaloniki, Greece. The study design was open but the biochemical analyses were blinded to the diagnosis and clinical information. An informed consent was obtained from all patients. This prospective study consisted of consecutive patients with and without XFS, who exhibited normal IOP (IOP less than $20 \mathrm{~mm} \mathrm{Hg}$ in at least two measurements separated by more than one day) and were undergoing routine senile cataract surgery for visual rehabilitation. Excluded were patients with other ophthalmic diseases (for example glaucoma, uveitis, progressive retinal disease etc), patients with systemic diseases (for example diabetes mellitus, arthritis), and patients who received local medications, or had undergone previous laser or intraocular surgery. The only systemic medications allowed in this study were those used for the control of systemic arterial hypertension, which were recorded in the study protocol.

All patients underwent a comprehensive ocular examination before enrolment. A slit lamp examination was performed, after pupillary dilatation, the day before phacoemulsification surgery to document the presence of signs consistent with XFS. All patients included had an IOP consistently below $20 \mathrm{~mm} \mathrm{Hg}$ and did not receive any local medication except artificial tears and mydriatics before cataract surgery. For the purposes of this study only patients exhibiting typical exfoliation material deposits on the lens and/or pupillary border were included. ${ }^{26}$

Patients did not receive any systemic premedication regime before cataract surgery. Blood pressure and heart rate were measured before cataract surgery. In all cases aqueous humour samples were obtained before conjunctival manipulation and before fashioning of the corneoscleral tunnel for phacoemulsification surgery. An attempt was made to keep all conditions uniform prior to aqueous acquisition (for example, duration of body rest in supine position in the operating theatre and the temperature of the operating theatre). A small amount of humour (15-40 $\mu \mathrm{l})$ was aspirated through an ab-externo limbal paracentesis site using a 27 gauge needle on a tuberculin syringe, with special care to avoid blood contamination. Immediately after collection, aqueous samples were stored at $-70^{\circ} \mathrm{C}$ until biochemical analysis. Samples that could not be evaluated within 4 months of storage were not included in this study.

This investigation included a total of 50 aqueous samples, 25 from cataract patients with XFS (mean age 70.9 (SD 7.9) years) and 25 from age matched cataract patients without XFS (mean age 70.8 (SD 7.7) years). There was no statistically significant difference between the two groups with regard to sex ( 10 males and 15 females in the XFS group $v 8$ males and 17 females in the control group; $\mathrm{p}=0.7688$ ).

All aqueous samples were examined the same day in a single assay, and were numbered according to the collection date. Clinical information was considered after completion of the assay.

\section{Endothelin measurement assay}

The aqueous concentration of ET- 1 was measured using a commercial immunoassay kit (Biomedica GmbH, Wien, Austria). The kit is a sandwich type enzyme linked immunoassay designed to determine endothelin (1-21) directly in biological fluids. The kit uses a 96 well plate precoated with a polyclonal antibody and a highly specific monoclonal detection antibody. It has a $100 \%$ crossreactivity for ET- 1 and ET-2, $<5 \%$ for ET-3, and $<1 \%$ for big endothelin 1 or 2 . A calibration curve was constructed using the standard
ET-1 solutions provided by the manufacturer with six standard solutions within a range of $0.16-8.0 \mathrm{pg} / \mathrm{ml}$. For the purposes of this study this kit assessed virtually only ET-1, as the kit uses ET-1 standards and the presence and biological effect of ET-2 in ocular tissues is considered negligible. ${ }^{27-30}$

Ten $\mu \mathrm{l}$ of aqueous samples diluted with $190 \mu \mathrm{l}$ of the assay buffer, provided by the manufacturer, were added to the appropriate wells. The ET-1 concentration measurement assay protocol was then followed according to the manufacturer's instructions. The lower detection limit of the assay was determined as the concentration of ET-1 measured at three standard deviations from zero along the calibration curve and was calculated to be $0.13 \mathrm{pg} / \mathrm{ml}$. Intra-assay variation was found to be $7.3 \%$ for a control concentration of about $8 \mathrm{pg} / \mathrm{ml}$ measured six times.

\section{Total protein measurement assay}

Total protein concentration in the aqueous humour was assessed with a microplate assay method, using the Coomassie Plus-200 protein assay reagent (Pierce Rockford, IL, USA). Bovine serum albumin was used as a standard. Five $\mu \mathrm{l}$ of standards or aqueous samples were mixed with $180 \mu \mathrm{l}$ of the reagent in 96 well plates. The absorbance at $595 \mathrm{~nm}$ was then measured in a stat-fax 21100 ELISA reader (Awareness Technologies Inc, Stuart, FL, USA)

\section{Statistical evaluation}

Statistical calculations were performed with the GraphPad InStat statistical package for Windows. Data are expressed as mean (standard deviation, SD). Normal distribution fitting was checked by the Kolmogorov-Smirnov Goodness of Fit test. Aqueous humour ET-1 and protein concentration, blood pressure, and heart rate were compared between the XFS group and the control group with the two tailed unpaired Student's $t$ test. Systemic medications and sex distribution of the groups were compared with the Fisher's exact test. Correlations between sets of data were estimated by Pearson correlation. p Values less than 0.05 were considered significant.

\section{RESULTS}

A total of 50 aqueous samples, 25 from cataract patients with XFS and 25 from age matched cataract patients without XFS were analysed. No difference was found before surgery between the two groups with regard to mean systolic blood pressure (156 (SD 11.2) $\mathrm{mm} \mathrm{Hg}$ in XFS $v$ 151.3 (SD $12.8) \mathrm{mm} \mathrm{Hg}$ in the controls; $\mathrm{p}=0.34)$, mean diastolic blood pressure (80.7 (SD 7.3) mm Hg in XFS patients $v$ 82.1 (SD 7.1) $\mathrm{mm} \mathrm{Hg}$ in the controls; $\mathrm{p}=0.62$ ) and mean heart rate (72.4 (SD 5.1) in XFS $v 74.4$ (SD 3.7) in the controls; $\mathrm{p}=0.28)$. In addition, no significant difference was documented in the mean IOP before surgery (16.4 (SD 1.7) $\mathrm{mm} \mathrm{Hg}$ in the XFS group $v 15.5$ (SD 1.5) $\mathrm{mm} \mathrm{Hg}$ in the controls; $p=0.053)$. There was no difference in the prevalence of arterial hypertension in the two groups (nine out of 25 in the XFS group $v 11$ out of 25 in the control group; $\mathrm{p}=0.773$ ).

The values of ET-1 passed the Kolmogorov-Smirnov normality test for both groups. The mean concentration of ET-1 in the aqueous samples from XFS patients was significantly greater $(4.6$ (SD 2.3 ) pg/ml; range $0.9-9.1 \mathrm{pg} /$ $\mathrm{ml}$ ) than that measured in the aqueous of age matched controls (2.8 (SD 1.71) pg/ml; range $0.5-5.9 \mathrm{pg} / \mathrm{ml})$; $(\mathrm{p}=0.006)$ (fig 1$)$. The values of total protein concentration also passed the Kolmogorov-Smirnov normality test for both groups. The mean total protein concentration in the aqueous humour from patients with XFS (0.380 (SD 0.159) mg/ml; range $0.106-0.806 \mathrm{mg} / \mathrm{ml}$ ) was significantly greater than that 


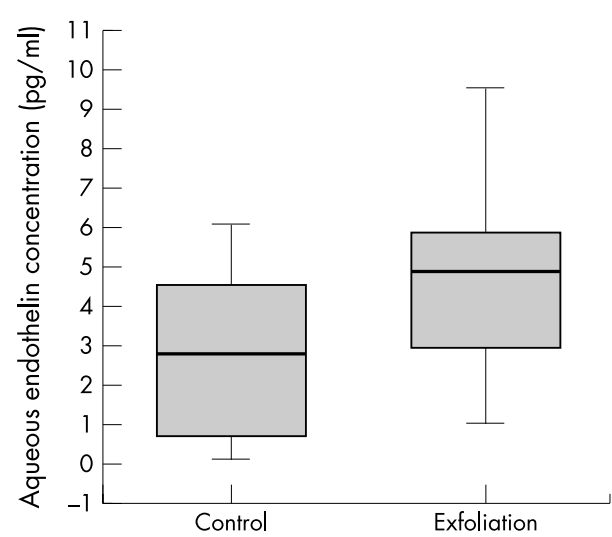

Figure 1 ET-1 concentration in the aqueous humour of cataract patients with and without XFS. A significantly higher concentration $(p=0.006)$ was found in the XFS samples.

of the age matched control patients $(0.279($ SD 0.144$) \mathrm{mg} / \mathrm{ml}$; range $0.085-0.542 \mathrm{mg} / \mathrm{ml}) ;(p=0.023$ ) (fig 2). However, no correlation could be established between ET-1 and total protein levels $(p=0.730)$ (fig 3$)$. Furthermore, ET-1 and protein concentrations did not correlate with age $(p=0.780$ and $\mathrm{p}=0.578$ respectively).

\section{DISCUSSION}

In the present study the human aqueous humour ET-1 concentration was measured in patients with XFS, to the best of our knowledge, for the first time employing a specific immunoassay. We documented a significantly higher concentration of ET-1 in the aqueous humour of patients with XFS compared with that of age matched controls. Increased endothelin levels have been found in the aqueous humour of patients with open angle glaucoma ${ }^{25}$ but importantly, our study shows a significant difference between normotensive patients with and without XFS. This implies an important role for ET-1 early in the process of the disease, before the development of XFG. It is not known how this increase in ET$\mathrm{l}$ in XFS influences the predisposition for the development of glaucoma in these patients.

The total protein concentration of the XFS group was also significantly higher than that of the control group, but the ET-1 level and the protein concentration did not show a correlation, thus implying that the increased level of ET- 1 in XFS is not due to the increased permeability of the blood aqueous barrier in XFS.

It has been reported that oxidative stress, mediated by reactive oxygen species, induces ET-1 expression in vascular smooth muscle cells ${ }^{31-33}$ and that $8-\mathrm{IPG}^{-\mathrm{F}_{2 a}}$ stimulates the secretion of ET-1 by endothelial cells. ${ }^{84}$ Furthermore, an increased aqueous humour concentration of TGF- $\beta 1$ and

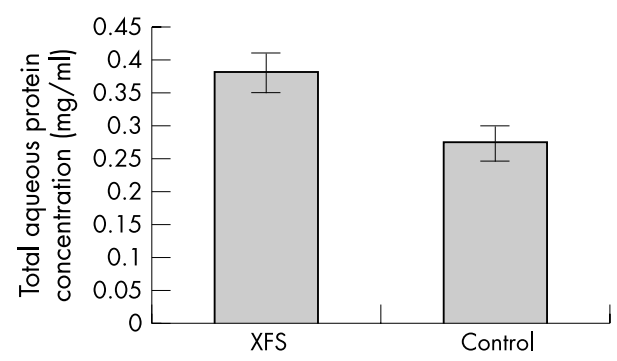

Figure 2 Protein concentration in the aqueous humour of patients with and without XFS. A significantly higher concentration $(p=0.023)$ was found in the XFS samples. Error bars represent standard deviation (SD).
8-IsoPGF 2 a has recently been documented in XFS. ${ }^{535-37}$ Since 8-IsoPGF 2 a a marker of the oxidative stress, stimulates ET-1 expression of endothelial cells ${ }^{84}$ it is reasonable to hypothesise that oxidative stress induces an increase of the aqueous humour ET-1 concentration in XFS by increasing 8-IsoPGF 2 a concentration in the aqueous. Furthermore it has been reported that oxidative stress and 8 - IsoPGF $_{2 a}$ induce TGF$\beta 1$ synthesis. ${ }^{38}{ }^{39}$ TGF- $\beta 1$ is known to further stimulate the synthesis of ET- $1 .{ }^{40}$ Accordingly, argon laser trabeculoplasty, a procedure associated with increased formation of free radicals in the anterior segment of the eye, ${ }^{21}$ caused a 7-12 fold increase in ET-1 concentration in the aqueous humour of rabbits. ${ }^{18-20}$ This increase was immediate and was associated with an increase of IOP. ${ }^{19}$ Therefore, it is reasonable to assume that the increased levels of TGF- $\beta 1$ in the aqueous humour of XFS patients may amplify the effect of oxidative stress on aqueous ET-1 concentration.

Endothelin-1 has been shown to contract ciliary smooth muscle cells and trabecular meshwork cells ${ }^{41}$ and to lower IOP in the monkey eye both by increasing aqueous humour outflow and by decreasing aqueous humour formation. ${ }^{42}$ The ET- 1 induced activation of the trabecular $\mathrm{ET}_{\mathrm{A}}$ receptors, ${ }^{14-16} 22$ can be blocked with specific $\mathrm{ET}_{\mathrm{A}}$ receptor antagonists both in the animal model and in human eyes. ${ }^{14} 1522$

$\mathrm{ET}_{\mathrm{A}}$ receptors were identified in the corneal endothelium, the ciliary non-pigmented epithelium, ciliary smooth muscle cells, and trabecular meshwork cells in vitro. ${ }^{43}$ Thus, increased aqueous ET-1 levels may be beneficial for the maintenance of a normal pressure level, ${ }^{23}$ but could have adverse pathophysiologic effects on the vasculature of anterior segment tissues, ${ }^{44}$ and increase the risk of glaucomatous neuropathy. ${ }^{45}$

Some studies have also suggested that ET-1, in addition to its vasoconstrictor function, promotes extracellular matrix synthesis and/or turnover. ${ }^{46}{ }^{47}$ Since excessive synthesis and progressive accumulation of abnormal extracellular material is a hallmark of XFS, there could be a direct effect of ET-1 upon matrix synthesis in the anterior segment of XFS eyes.

The important role of ET-1 in ocular vasoconstriction has been demonstrated in the retina, choroid, and optic nerve head. ${ }^{11}{ }^{12} 45$ Chronic administration of ET-1 in monkeys has been reported to induce optic nerve ischaemia. ${ }^{12} 48$ In addition, ET-1 has been shown to induce glaucoma like optic nerve head damage if injected into the posterior vitreous, or chronically applied to the optic nerve in animal experiments. ${ }^{11}{ }^{13}$ Such observations suggest that ET-1 can cause local ocular ischaemia and can contribute to the vascular abnormalities and progressive obliterative vasculopathy, which are commonly seen in XFS eyes. In particular, XFS is associated with a clinically, angiographically, and morphologically well documented iris vasculopathy, with manifestations of blood aqueous barrier defects, vessel dropout, microneovascularisation, hypoperfusion, and anterior chamber hypoxia. ${ }^{49-51}$ It is reasonable to assume that these vascular abnormalities of the iris are associated with the higher aqueous level of ET-1 reported in this study. This assumption is further supported by an immunohistochemical study showing the presence of ET-1 in the human ciliary body, choroid, and iris stroma. ${ }^{52}$

Since the vitreous concentration of ET- 1 in XFS and XFG remains as yet unknown, it is uncertain whether ET-1 plays a contributing role in the development of the glaucomatous optic neuropathy in XFG. Future studies on the aqueous and vitreous ET- 1 concentration in patients with XFG may clarify the role of ET-1 in the development and progression of XFG. It is also conceivable that the increased aqueous ET-1 concentration in patients with XFS may be an independent risk factor for optic nerve damage. Further research is required to correlate ET-1 aqueous humour concentration 


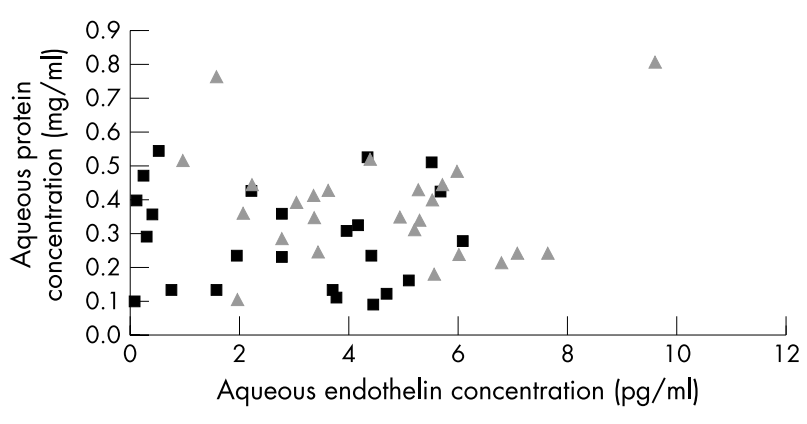

Figure 3 No correlation could be established between aqueous protein and endothelin 1 concentrations $(p=0.730)$. Control samples are symbolised with quadrants and exfoliation samples are symbolised with triangles.

in patients with XFS and ocular hypertension, and patients at various stages of XFG with their clinical parameters (degree of visual field loss and optic nerve head damage) to further elucidate this hypothesis.

An increase in aqueous total protein concentration indicating a blood aqueous barrier breakdown has been observed in rabbit and cat eyes after intracameral ET-1 administration..$^{53}$ Although the total protein concentration was significantly higher in XFS eyes in our study no correlation could be established between aqueous humour ET-1 levels and total protein concentration. This indicates that the increased ET-1 levels in XFS eyes are not related to an increase in permeability of the blood aqueous barrier, but to local increased synthesis and secretion of ET-1. A likely source of ET-1 in the aqueous humour could be the ciliary epithelium, which has been shown to synthesise and secrete ET-1 in vitro. ${ }^{17}$ This study did not record the plasma ET-1 concentration. Although in a previous study the plasma concentration of ET-1 in patients with XFG did not differ from that of healthy controls, ${ }^{55}$ this could be due to the assay used and is therefore an important topic for future investigation.

In summary, we have documented significantly increased aqueous humour ET-l concentrations in patients with XFS and normal IOP compared with that of age matched control patients without XFS. The findings suggest a pathophysiologic role for ET-1 in XFS. Although our study does not include angiographic comparisons we suggest that the increase in aqueous ET-1 may provide an explanation for the characteristic vascular alterations in the anterior segment of patients with XFS. Further research is required to clarify the role of ET- 1 in the development of raised IOP in individuals with XFS, the progression to XFG, and the possibility of increased susceptibility to glaucomatous damage in patients with XFG.

\section{ACKNOWLEDGEMENTS}

The authors acknowledge the excellent technical assistance of Ms Melpomeni Christophoridou and the help of Dr Ioannis Tersis with the aqueous samples.

\section{Authors' affiliations \\ G G Koliakos, Dept of Biological Chemistry, Aristotle University, Thessaloniki, Greece}

A G P Konstas, S Maloutas, N Georgiadis, University Dept of Ophthalmology, AHEPA Hospital, Thessaloniki, Greece

U Schlötzer-Schrehardt, Dept of Ophthalmology, University of ErlangenNürnberg, Erlangen, Germany

G Hollo, 1 st Dept of Ophthalmology, Semmelweis University, Budapest, Hungary

D Mitova, Dept of Ophthalmology, Medical University of Varna,

Bulgaria

D Kovatchev, Dept of Biology, Medical University of Varna, Bulgaria
Supported by grant 912-OPT-0091-149 from Pharmacia (New Jersey, USA), and by the national grants ENTER and PENED to Dr AGP Konstas and by national grant ETT $011 / 2003$ to Dr G Hollo.

\section{REFERENCES}

1 Ritch R, Schlotzer-Schrehardt U. Exfoliation syndrome. Surv Ophthalmol 2001;45:265-315.

2 Ritch R. Exfoliation syndrome: more than meets the eye. Acta Ophthalmol Scand 2002;80:465-7.

3 Ritch R, Schlotzer-Schrehardt U, Konstas AGP. Why is exfoliation syndrome associated with glaucoma? Prog Ret Eye Res 2003;22:253-75.

4 Koliakos GG, Konstas AG, Schlotzer-Schrehardt U, et al. Ascorbic acid concentration is reduced in the aqueous humor of patients with exfoliation syndrome. Am J Ophthalmol 2002;134:879-83.

5 Koliakos GG, Konstas AG, Schlotzer-Schrehardt U, et al. 8-Isoprostaglandin F2a and ascorbic acid concentration in the aqueous humour of patients with exfoliation syndrome. Br J Ophthalmol 2003;87:353-6.

6 Schlotzer-Schrehardt U, Lommatzsch J, Kuchle M, et al. Matrix metalloproteinases and their inhibitors in aqueous humor of patients with pseudoexfoliation syndrome/glaucoma and primary open-angle glaucoma. Invest Ophthalmol Vis Sci 2003:44:1117-25.

7 Gartaganis SP, Georgakopoulos CD, Mela EK, et al. Matrix metalloproteinases and their inhibitors in exfoliation syndrome. Ophthalmic Res 2002;34:165-71.

8 Fukunaga M, Yura T, Badr KF. Stimulatory effect of 8-Epi-PGF2 alpha, an F2isoprostane, on endothelin-1 release. J Cardiovasc Pharmacol 1995;26(Suppl 3):S51-S52.

9 Fernandez-Patron C, Radomski MW, Davidge ST. Vascular matrix metalloproteinase-2 cleaves big endothelin-1 yielding a novel vasoconstrictor. Circ Res 1999;85:906-11.

10 Yorio T, Krishnamoorthy R, Prasanna G. Endothelin: is it a contributor to glaucoma pathophysiology? J Glaucoma 2002;11:259-70

11 Orgul S, Cioffi GA, Wilson DJ, et al. An endothelin-1 induced model of optic nerve ischemia in the rabbit. Invest Ophthalmol Vis Sci 1996;37:1860-9.

12 Orgul S, Cioffi GA, Bacon DR, et al. An endothelin-1-induced model of chronic optic nerve ischemia in rhesus monkeys. J Glaucoma 1996;5:135-8.

13 Haefliger IO, Flammer J, Beny JL, et al. Endothelium-dependent vasoactive modulation in the ophthalmic circulation. Prog Retin Eye Res $2001 ; 20: 209-25$.

14 Kawamura $\mathrm{H}, \mathrm{Oku} \mathrm{H}$, Li Q, et al. Endothelin-induced changes in the physiology of retinal pericytes. Invest Ophthalmol Vis Sci 2002;43:882-8.

15 Polak K, Petternel V, Luksch A, et al. Effect of endothelin and BQ123 on ocular blood flow parameters in healthy subjects. Invest Ophthalmol Vis Sci 2001;42:2949-56.

16 Wiederholt $M$, Thieme $H$, Stumpff F. The regulation of trabecular meshwork and ciliary muscle contractility. Prog Retin Eye Res 2000;19:271-95.

17 Lepple-Wienhues A, Becker M, Stahl F, et al. Endothelin-like immunoreactivity in the aqueous humour and in conditioned medium from cultured ciliary epithelial cells. Curr Eye Res 1992;11:1041-6.

18 Hollo G Lakatos P. Increase of endothelin-1 concentration in aqueous humour induced by argon laser trabeculoplasty in the rabbit. A preliminary study. Acta Ophthalmol Scand 1998;76:289-93.

19 Hollo G, Lakatos P, Vargha P. Immediate increase in aqueous humour endothelin 1 concentration and intra-ocular pressure after argon laser trabeculoplasty in the rabbit. Ophthalmologica 2000;214:292-5.

20 Guzey M, Vural H, Satici A. Endothelin-1 increase in aqueous humour caused by frequency-doubled Nd:YAG laser trabeculoplasty in rabbits. Eye 2001;15:781-5.

21 Guzey M, Vural H, Satici A, et al. Increase of free oxygen radicals in aqueous humour induced by selective $\mathrm{Nd}$ :YAG laser trabeculoplasty in the rabbit. Eur J Ophthalmol 2001;11:47-52.

22 Hollo G, Kothy $P$, Lakatos $P$, et al. Endothelin-A receptor antagonist BQ-485 protects against intraocular pressure spike induced by laser trabeculoplasty in the rabbit. Ophthalmologica 2002;216:459-62.

23 Sugiyama K, Haque MS, Okada K, et al. Intraocular pressure response to intravitreal injection of endothelin-1 and the mediatory role of ETA receptor, ETB receptor, and cyclooxygenase products in rabbits. Curr Eye Res 1995; 14:479-86.

24 Noske W, Hensen J, Wiederholt M. Endothelin-like immunoreactivity in aqueous humor of patients with primary open-angle glaucoma and cataract. Graefes Arch Clin Exp Ophthalmol 1997;235:551-2.

25 Tezel G, Kass MA, Kolker AE, et al. Plasma and aqueous humor endothelin levels in primary open-angle glaucoma. J Glaucoma 1997;6:83-9.

26 Prince AM, Streeten BW, Ritch R, et al. Preclinical diagnosis of pseudoexfoliation syndrome. Arch Ophthalmol 1987;105:1076-82.

27 Ramachandran E, Frank RN, Kennedy A. Effects of endothelin on cultured bovine retinal microvascular pericytes. Invest Ophthalmol Vis Sci 1993;34:586-95.

28 Chakravarthy U, Douglas AJ, Bailie JR, et al. Immunoreactive endothelin distribution in ocular tissues. Invest Ophthalmol Vis Sci 1994;35:2448-54.

29 Nosaka C, Ishikawa H, Haruno I, et al. Radioligand binding characteristics of the endothelin receptor in the rabbit iris. Jpn J Pharmacol 1998;76:289-96.

30 Wu KY, Hong SJ, Lin CP, et al. Endothelin-induced changes of secondary messengers in cultured corneal endothelial cells. J Ocul Pharmacol Ther 2001;17:351-61.

31 Ruef J, Moser M, Kubler W, et al. Induction of endothelin-1 expression by oxidative stress in vascular smooth muscle cells. Cardiovasc Pathol $2001 ; 10: 311-15$. 
32 Kahler J, Ewert A, Weckmuller J, et al Oxidative stress increases endothelin-1 synthesis in human coronary artery smooth muscle cells. J Cardiovasc Pharmacol 2001;38:49-57.

33 Kaehler J, Sill B, Koester R, et al. Endothelin-1 mRNA and protein in vascular wall cells is increased by reactive oxygen species. Clin Sci (Lond) 2002;103(Suppl 48):S176-S8.

34 Yura T, Fukunaga M, Khan R, et al. Free-radical-generated F2-isoprostane stimulates cell proliferation and endothelin-1 expression on endothelial cells. Kidney Int 1999;56:471-8.

35 Schlotzer-Schrehardt $U$, Zenkel M, Kuchle $M$, et al. Role of transforming growth factor-betal and its latent form binding protein in pseudoexfoliation syndrome. Exp Eye Res 2001;73:765-80.

36 Koliakos GG, Schlotzer-Schrehardt U, Konstas AG, et al. Transforming and insulin-like growth factors in the aqueous humour of patients with exfoliation syndrome. Graefes Arch Clin Exp Ophthalmol 2001;239:482-7.

37 Schlotzer-Schrehardt U, Kuchle M, Hofmann-Rummelt C, et al. [Latent TGFbeta 1 binding protein (LTBP-1); a new marker for intra-and extraocular PEX deposits]. Klin Monatsbl Augenheilkd 2000;216:412-19.

38 Montero A, Munger KA, Khan RZ, et al. F(2)-isoprostanes mediate high glucose-induced TGF-beta synthesis and glomerular proteinuria in experimental type I diabetes. Kidney Int 2000;58:1963-72.

39 Weiss MF, Scivittaro V, Anderson JM. Oxidative stress and increased expression of growth factors in lesions of failed hemodialysis access. Am J Kidney Dis 2001;37:970-80.

40 Markewitz BA, Farrukh IS, Chen Y, et al. Regulation of endothelin-1 synthesis in human pulmonary arterial smooth muscle cells. Effects of transforming growth factor-beta and hypoxia. Cardiovasc Res 2001:49:200-6.

41 Pang IH, Yorio T. Ocular actions of endothelins. Proc Soc Exp Biol Med 1997;215:21-34.

42 Erickson-Lamy K, Korbmacher C, Schuman JS, et al. Effect of endothelin on oufflow facility and accommodation in the monkey eye in vivo. Invest Ophthalmol Vis Sci 1991;32:492-5.
43 Tao W, Prasanna G Dimitrijevich S, et al Endothelin receptor A is expressed and mediates the [Ca2+]i mobilization of cells in human ciliary smooth muscle, ciliary nonpigmented epithelium, and trabecular meshwork. Curr Eye Res 1998;17:31-8.

44 Sugiyama K, Haque MS, Onda E, et al. The effects of intravitreally injected endothelin- 1 on the iris-ciliary body microvasculature in rabbits. Curr Eye Res 1996; 15:633-7.

45 Oku H, Sugiyama T, Kojima S, et al. Experimental optic cup enlargement caused by endothelin-1-induced chronic optic nerve head ischemia. Surv Ophthalmol 1999;44(Suppl 1):S74-S8.

46 Guarda E, Katwa LC, Myers PR, et al. Effects of endothelins on collagen turnover in cardiac fibroblasts. Cardiovasc Res 1993;27:2130-4.

47 Xu SW, Denton CP, Dashwood MR, et al. Endothelin-1 regulation of intercellular adhesion molecule- 1 expression in normal and sclerodermal fibroblasts. J Cardiovasc Pharmacol 1998;31(Suppl 1):S545-S7.

48 Cioffi GA, Sullivan P. The effect of chronic ischemia on the primate optic nerve. Eur J Ophthalmol 1999;9(Suppl 1):S34-S6.

49 Konstas AG, Dutton GN. Gonioscopic findings in Greek patients with exfoliation glaucoma. Acta Ophthalmol (Copenh) 1991;69:281-7.

50 Konstas AG, Williamson TH. Co-existence of exfoliation syndrome, previous iris surgery, and heterochromia. Acta Ophthalmol (Copenh) 1993;71:850-2.

51 Helbig H, Schlotzer-Schrehardt U, Noske W, et al. Anterior-chamber hypoxia and iris vasculopathy in pseudoexfoliation syndrome. Ger J Ophthalmol 1994:3:148-53.

52 Wollensak G, Schaefer HE, Ihling C. An immunohistochemical study of endothelin-1 in the human eye. Curr Eye Res 1998;17:541-5.

53 Granstam E, Wang L, Bill A. Effects of endothelins (ET-1, ET-2 and ET-3) in the rabbit eye; role of prostaglandins. Eur J Pharmacol 1991;194:217-23.

54 Granstam E, Wang L, Bill A. Ocular effects of endothelin-1 in the cat. Curr Eye Res 1992;11:325-32.

55 Hollo G, Lakatos P, Farkas K. Cold pressor test and plasma endothelin-1 concentration in primary open-angle and capsular glaucoma. J Glaucoma 1998;7:105-10. 